\title{
Imágenes y significación
}

\author{
Images and Meaning \\ Imagens e significado
}

Ricardo Pardo Ruiz y Claudia del Pilar Vélez De La Calle²

Recibido: 13/07/2015 - Aceptado: 23/09/2015

\begin{abstract}
Resumen
La ciencia de carácter positivo desconoció a la imagen como fuente de significación de la realidad. El artículo recoge y analiza las distintas maneras en las que esta ruptura sobrevivió durante el siglo XX, y las formas como al mismo tiempo fue complejizándose el concepto de imagen, deviniendo en una serie de posturas que hoy lo vinculan con mayor fuerza a la búsqueda de significaciones y sentidos. En las conclusiones se puntualizan tres factores decisivos en el distanciamiento con la tradición y la configuración de un nuevo horizonte de comprensión sobre el vínculo imagen - significación, que se sugiere abierto a las Ciencias Sociales y Humanas.
\end{abstract}

Palabras clave: imagen - significación - lenguaje - lógica - sentidos realidad - conciencia.

\begin{abstract}
The science of positive character ignored the image as a source of meaning of the reality. The article presents and analyzes the different ways in which this break survived in the twentieth century, and the ways the image concept was becoming complex emerging different kinds of postures that today most strongly linked to the search for meanings and senses. The conclusions point out three key factors in the distance with tradition and setting up a new horizon of understanding of the link image - meaning suggested to the social and human sciences.
\end{abstract}

Keywords: image - meaning - language - logic - sense - reality - consciousness.

1 Estudiante del Doctorado en Ciencias Sociales, Niñez y Juventud. Alianza CINDEUniversidad de Manizales.

2 Postdoctora en Educación y Estudios Culturales. Docente Doctorado Cinde/U Manizales. 


\section{Resumo}

A ciência de caráter positivo ignorou a imagem como uma fonte de sentido da realidade. $\mathrm{O}$ artigo recolhe e analisa as diferentes formas em que esta ruptura sobreviveu durante o século $X X$, e as formas como ao mesmo tempo, foi se complejizando o conceito de imagem, tornando-se numa série de posturas que hoje é vinculada com mais forca na procura de significados e sentidos. Nas conclusões apontam-se três fatores decisivos no distanciamento com a tradição e a configuração de um novo horizonte de compreensão sobre o vinculo imagem - significação, que se sugere aberta para as Ciências Sociais e Humanas.

Palavras-chave: Imagem - significação - linguagem - lógica - sentidos, realidade - consciência.

\section{Introducción}

En el presente artículo se pretende analizar el devenir de la imagen como concepto vinculante a la realidad dentro del desarrollo de las tradiciones del pensamiento, confluentes en el siglo XX y el panorama que desde allí se ha proyectado para la imagen como campo de estudio de la realidad. La relación imagen - realidad se plantea en el entendido que las figuraciones colectivas sobre los objetos del mundo encierran el origen de las significaciones sobre éste. La trama del concepto de imagen, sin embargo, no podrá darse sólo en torno a esta disquisición, es necesario desagregar el vínculo que une lenguaje y realidad para abrirse paso hacia su presente. Tanto la imagen como el lenguaje centran la cuestión sobre el origen de la significación, es decir, sobre el lugar en el que toman por primera vez forma los significados.

Por un lado, la tradición supondrá que los significados sobre la realidad no sólo se representan mediante formas del lenguaje sino que el pensamiento mismo se configura en la estructura del lenguaje. Una posición diferente estará identificada con la idea de que el lenguaje no tendría por qué ser una instancia de fondo sobre la cual se construyen los significados y de donde provendría el orden del pensamiento, así que la significación debe obedecer a formas no verbales como las icónicas. Ambos lugares de enunciación hubieron de devenir en posturas más o menos sucedáneas, sin marcar una real confrontación 
entre ellas; historia que vino a marcarse con énfasis en todo el transcurso del siglo XX.

Han sido diversas las corrientes de pensamiento en las que ha tomado forma la discusión acerca del origen de las significaciones, o bien, acerca de la naturaleza del sentido, y en las que se trasluce la idea de imagen, muchas veces como subsidiaria del lenguaje y otras, pero sólo hasta hace poco, como su contraparte. El artículo revisa el desarrollo de esta tensión en seis apartados a saber, la tradición lingüística y su ruptura, la fenomenología, el psicoanálisis, la imagen como síntesis de sensaciones, hacia una lógica icónica, y un último tramo a manera de conclusiones.

\section{Tradición y ruptura de la lingüística}

Por mucho tiempo, la cuestión que reúne al lenguaje y al pensamiento se ha mantenido en un estado imperturbable, como parte de algo que Cassirer denominó lógica arcaica. La cuestión de si el lenguaje es la forma que adquiere el pensamiento para hacerse del mundo, ha demostrado poder sobrellevarse con una pasmosa naturalidad, como si el lenguaje fuese algo y mantuviera una identidad con el pensamiento fuera de toda intervención humana. No obstante, la filosofía del siglo XX habrá de romper por momentos el hechizo de esta unión.

En las décadas que unieron el siglo XIX con el XX la relación entre lenguaje y pensamiento se vio exacerbada en la égida lingüística. La tradición lingüística representa todo lo que de fondo existe en el racionalismo moderno, tradición que puede retrotraerse hasta la formulación eleática que equipara lenguaje y pensamiento. Los lingüistas entendieron la lengua como un sistema, el más especial de los sistemas semiológicos, cuyos elementos se conjugan como valores puros, que van cambiando de acuerdo a la posición relativa de los demás términos, obedeciendo principios de economía y equivalencia.

Puede esgrimirse que la supuesta identidad entre lenguaje y pensamiento no ha sido planteada explícitamente por parte de los lingüistas, así bien, ni Saussure ni Jakobson aceptarían que el lenguaje es 
intrínseco al pensamiento, solo que sirve de medio para expresarlo. Saussure (citado por Courvez, 2005) ha dicho que el pensamiento es una "masa amorfa e indistinta" donde no hay elementos diferenciados, como tampoco existen en tanto sustancias fónicas, es decir que tal paralelismo entre pensamiento y lenguaje no puede darse taxativamente.

Empero, la relación entre lenguaje y pensamiento en Saussure no se plantea de manera condicional: finalmente, al producirse el acto lingüístico, la sustancia fónica y el pensamiento se articulan, logrando que los pensamientos puedan servirse de las palabras. Habría que admitir que tal relación, si bien no se plantea como substancial, profundiza el hecho de que el pensamiento es soluble en los significantes.

En el fondo, admite Buxó en el prefacio de Elementos de la Semiología, la reflexión lingüística intenta constreñir toda configuración semántica, aun cuando ésta se despliegue en una amplia zona de realidad psíquica y social, al ámbito de las invariantes de la lengua, es decir,

(...) a los modos de significar propios de las unidades léxicas o sintagmáticas que, en cierta medida, solapan la presencia de paradigmas translingüísticos (ideológicos) que intervienen de manera decisiva tanto en la constitución de los enunciados verbales como en la asignación de funciones discursivas (sociales) a los procesos de enunciación. (Barthes 2000 p. 14).

En general, la convicción con la que se asumió el problema del lenguaje durante el siglo pasado mantuvo implícito el dogma que desde siempre evitó poner en cuestión el orden lenguaje - pensamiento. Los trabajos de Barthes y Chomsky promediando el siglo, a pesar de que irían a introducir nuevas conclusiones en la teoría lingüística y semiótica, no darían al traste con la tradición; por el contrario, ahondarían en la concepción del lenguaje como instancia fundamental de significación. Barthes se ocupó de la imagen entendiéndola como signo icónico, no obstante la imagen no podrá constituir, según él, un objeto significante en estado puro, siempre habrá intervención del lenguaje como intermediario, por eso no es justo afirmar que nos encontremos exclusivamente en una cultura de la imagen (Barthes 
1997 pág. 246). Chomsky por su parte, argumentó la teoría de un sistema de reglas invariantes que se armonizan bajo los principios de economía y concepción óptima, posibilitando la generación de la lengua más allá de las particularidades de esta. La conclusión se extrema del lado del lenguaje, toda vez que supone que las formas del lenguaje preexisten a las formas del pensamiento.

El estudio de la imagen se mantuvo subordinado a la concepción de que todos los elementos asociados a un significado están inmersos en un sistema, cuya naturaleza es apenas discernible fuera de él y que posibilita la unidad y el valor de los significantes. De esa manera, las imágenes terminan siendo objetos de análisis de la semiótica, solo en consideración a que funcionan como signos, cuyos significados aguardan una instancia de fondo para sintetizarse. En este orden, existirían sistemas icónicos a la par con otros sistemas semióticos.

Entendiendo lo anterior, se puede decir que no cambia en nada el curso de esta historia tomar partido por la imagen como elemento semiótico; sólo cuando se pone en paréntesis el concepto mismo de sistema como nivel fundamental de organización del lenguaje, se logra abrir paso a ciertas posturas divergentes a la tradición lingüística que reivindicaron la relación imagen - realidad bien entrada la segunda mitad del siglo.

Durante este periodo, corrientes filosóficas distintas habrían de ahondar en el lenguaje no como fruto de la misma tradición, sino como dimensión que encomia lo humano más allá de la vana certidumbre de que las formas lingüísticas coinciden con el pensamiento, en una dirección claramente opuesta a la que entroncaba el conjunto de la filosofía moderna. La convicción aún latente que equiparaba lenguaje y pensamiento será atribuida a un manifiesto logocentrismo, del que Durand advierte cuando encuentra en la idea del ser una identidad reductible a su expresión lingüística, como si mediante la palabra, el ser se diera de manera inmediata.

El lenguaje, como producto de esta nueva mirada, se despoja de su pretensión formal para servir de envés a la pregunta renovada sobre el hombre. El lenguaje se afirma como fundamental, pero no por la 
univocidad de sus reglas, sino porque logra recomponer el vínculo del hombre con su ser. En consonancia, la discusión sobre el lenguaje no podría subsistir al margen de lo humano, es decir, sin poner de presente que el lenguaje no existe por fuera del hombre. La equivalencia entre el lenguaje y la realidad pierde sentido frente a la convicción heideggeriana que enuncia al hombre como fundado en la palabra. La palabra no es el lenguaje, pues ésta se haya desembargada de él. Pero tampoco se trata de la palabra como se suele entender -dice Heidegger interpretando a Hölderlin-, es decir, asumiéndola como el conjunto fijo de vocablos y de reglas para unirlos (1994 26).

Para Cassirer la tesis que reúne lenguaje y pensamiento, enunciada en tantas formas y momentos, resulta incompleta de dos maneras distintas. Primero, porque se excluyen aquellas formas de pensamiento conceptual en las que éste se libera del lenguaje, y segundo, porque reduce el lenguaje al ámbito lógico, "al ámbito de los conceptos, juicios y razonamientos".

El poder de la forma lingüística no se agota en aquello que rinde como vehículo y medio del pensamiento lógico-discursivo. El lenguaje impregna ya la concepción y configuración intuitivas del mundo y no en menor escala participa en la construcción del reino de los conceptos, en la estructuración de la percepción y en la de la intuición (Casssirer 1998 144).

La fuerza con la que se desarrolló la lingüística después de la década de 1880 y el carácter propio con el que logró influir el comienzo del siglo XX tiene origen en una suerte de episteme que enraíza la cuestión hasta la lógica aristotélica, y que Durand (1993) fundamenta en dos principios. El primero, lo llama el del Intercambio hipostasiado (p. 46) o generalizado, y determina la concepción de que el lenguaje contiene en sí mismo la capacidad de dar sentido, algo que De Mauro concierta y advierte, "el error radica en la afirmación y en la creencia de que las palabras y las frases significan algo" (citado por Durand 1993 47). El lingüista extiende la idea, venida de la ciencia, acerca de la transparencia del lenguaje, como condición para entender el concepto del lenguaje en general. Un segundo principio tiene expresión 
en el binarismo (p. 54), que entraña el lenguaje desde su estructura para separar hasta la más mínima articulación sémica a través de dos valores opuestos.

\section{La fenomenología}

Los trabajos de Husserl, nacidos en los primeros años del siglo, se constituían en una línea de batalla frente al psicologismo. Dicha oposición tenía que ver con el propósito de contener en la condición humana toda explicación sobre ella, de esa manera, al preguntar por el origen del sentido se evitaba remontar lo propiamente humano y arrojar tal cuestión a la espesura de la inconciencia, donde todo puede tener lugar sin que una razón medie para ello.

Para Husserl no es concebible que las significaciones provengan de una fuente desprovista de una razón objetiva. La significación no puede depender de una trama de contenidos psicológicos que permanezca en una suerte de movimiento fortuito; sin arraigo a principios lógicos, la significación ha de depender exclusivamente de una intención significativa. Si se oye el nombre de alguien o de algo y se piensa en él, debe decirse que el significado de ese nombre referido se cumple en la intención significativa, a pesar de que existan unos contenidos imaginables fuertemente ligados a ese nombre. El significado no cambiará en nada si esos contenidos imaginativos varían en el acto de pensamiento. Si aquello a lo que refiere ese nombre es por ejemplo una montaña, su significado permanecerá intacto sin importar que se imagine bajo una luz matinal o una luz vespertina. Así, "la esencia de expresar reside en la intención significativa y no en las imaginaciones (...) si tales imaginaciones existen, están íntimamente fundidas en la intención significativa" (Husserl 1999 286).

La posible relación entre la significación y las imágenes es puesta de plano como insustancial; las imágenes que son por excelencia tales contenidos psicológicos, se muestran como circunstanciales e inconexas, de allí que no puedan constituir la síntesis del significado. Los argumentos sobre dicha afirmación giran alrededor de la idea 
de que la imagen es un contenido que se da relacionado con los elementos sensibles de una vivencia, los cuales pueden ser diversos y caóticos. Husserl confía en que tras dicha diversidad existe una esencia que coincide totalmente con lo expresado. Algo que puede ser considerado como un concepto en el sentido de objeto universal. Por supuesto, esos objetos no son modelos que tienen existencia en algún lugar, sino que son constitutivos de la realidad, son ideales pero en su singularidad. Estos objetos ideales mantienen con los actos de significar una relación como la que tiene la especie rojo con las rayas rojas que tiene un pastel, cada raya tiene, además de otros aspectos constitutivos como la extensión y la forma, su propio rojo, es decir, su caso particular.

Husserl pone de manifiesto, con todo el peso del racionalismo, la absoluta congruencia que encuentra entre la propia intención significativa y el lenguaje. La forma en que esto se afirma en su obra puede resumirse de la siguiente manera: "Todo lo que es, es cognoscible en sí y su ser es un ser de determinado contenido. Lo que está determinado en sí fijamente, debe poder determinarse objetivamente, y lo que se puede determinar objetivamente ha de poder expresarse -hablando idealmente- en significaciones verbales fijamente determinadas" (Ídem, p. 280).

Tal convicción pierde sentido en la obra de Bergson. Para él la filosofía, que tiene como misión dirigirse a lo inmediato y originario, no puede ver en la conceptualización, obra cumbre del lenguaje, más que un falseamiento de la realidad; por consiguiente su filosofía, que es metodológicamente intuición, buscará expresar en imágenes lo que no puede lograr con los conceptos.

En sus aspectos más generales el pensamiento de Bergson privilegia las imágenes sobre el lenguaje como posibles vinculantes de la realidad. Sin embargo, deja claro que hay un sustrato que precede la expresión de las imágenes, es decir, que las imágenes son expresión de algo anterior. De allí entonces, el concepto de esquema: Al nivel de la imagen y al nivel en el que se puede suponer la relación entre las imágenes, no se puede pactar la complejidad de la realidad, debe 
existir un nivel superior en el que las imágenes se asocien, pues éstas no se suceden ni de manera mecánica, ni su continuidad se da en relación a una forma o apariencia común. Lo que entra en juego es una capacidad vinculante de las imágenes en función de su significación, por tanto, se trata de un nivel distinto, que se organiza en el concepto de esquema. El esquema es la palestra donde se organizan las percepciones y adquieren así significado.

No obstante, la tendencia a ver en las imágenes una suerte de componentes monolíticos alternándose en una estructura de significación, por no ver, en su lugar, procesos, derivó una concepción negativa de las imágenes por parte de Bergson. Al entenderlas como unidades inmóviles, las imágenes falsificarán la realidad, en tanto ofrecen de ella una apariencia estática. Bergson negará de esa forma que la imagen pueda constituir el todo de la vida mental; de ser así, ver las palabras y pronunciarlas no guardaría ninguna diferencia con entender lo que ellas unidas significan. La cuestión es que el pensamiento puede realizarse en imágenes pero siempre será distinto a ellas, hay algo que lo constituye como simple y abstracto previamente (Bergson 1994).

La obra de Sartre dedicada a la Imagen aparecerá años después. Puede decirse que sólo hasta entonces el concepto de imagen logra enfocarse como problema central. Con respecto a la relación entre ésta y las significaciones, Sartre no se adecúa a las conclusiones de Husserl, encuentra en él la misma privación conceptual que ha impedido la comprensión del fenómeno de la imagen en el seno de otras posturas teóricas, esto es, al asumir que la imagen se produce fuera del pensamiento. Sartre (2005) se pregunta entonces: ¿En qué estado puede estar la imagen al situarse fuera del pensamiento? "¿Qué sería de la imagen fuera de la síntesis de significado?" (p. 85).

Sartre tuvo claro que cuando se constituye la imagen, se hace por el saber de algo, y ese saber define una intención, pues no se trata de un simple saber, sino de un acto, es lo que se quiere representar (ídem). Al imaginar la montaña, por ejemplo de un color amarillo -volviendo al ejemplo mencionado-, se debe aceptar que esta imagen consti- 
tuye un saber, y ese saber no se ha dado como indeterminado sino que trata de aprehenderse así, de un color o de un cierto tamaño. La cuestión que reúne imagen y significación queda subsumida a un solo momento, la intención significativa no se proyecta en un momento distinto al de la existencia de la imagen.

No obstante y a pesar de que para Sartre la imagen es ya el saber de algo, bien puede existir el saber sin la imagen. En ese sentido Sartre había hecho pie en los estudios experimentales que dominaron la atmósfera de la psicología alemana en el albor del siglo. En la escuela de Würzburg se habían planteado el propósito de reconocer a través de experimentos, los diferentes elementos visuales, acústicos y de sensaciones táctiles intercalados entre la recepción y la respuesta a ciertas pruebas mentales, dirigidas a los participantes. Pronto, la cuestión sobre lo que ocurre cuando se piensa, tomará un nuevo camino. Las experiencias mostraban ciertas clases de procesos concientes que no se daban en imágenes, y se consideraron como difusas y abstractas, algo que Ach llamó actos de conciencia, es decir, un saber conciente sin imágenes (Arnheim 1986 112). En cualquier caso, para Sartre estos estados no pueden traducirse en la existencia de una conciencia vacía, la sola combinación semántica es contradictoria porque la conciencia se presenta ya intencionada hacia algo. A lo sumo, tales experiencias demostraban cómo el saber de algo se puede apartar en extremo de las intuiciones sensibles, pero siempre existirá una tendencia del saber hacia la imagen, como lo lee en los experimentos de Burloud, donde se concluye que no puede existir una conciencia de puro significado pues ésta siempre estará íntimamente ligada con lo sensible.

En esa dirección Sartre se opondrá tanto a Husserl como a Bergson, casi del mismo modo que lo hizo frente al psicoanálisis. La idea de Husserl de una "intención significativa", es decir, de una tendencia a llenar esa conciencia (vacía) de significado y el concepto de Bergson sobre un esquema conciben erróneamente -según Sartre- que pensamiento e imagen se constituyen en momentos y bajo naturalezas distintas. 


\section{Psicoanálisis}

La teoría de Freud representa otro camino por el cual pensar el vínculo imagen-significación. La salida que defendió el psicoanálisis fue el vínculo a una realidad de hecho, de carácter filogenética. Para el psicoanálisis no existe un esquema o algo parecido, se trata de una fuente más primaria y biológica. La existencia y sucesión de las imágenes está proscrita a un estado inferior, caótico, que será el inconsciente. En tal nivel se tensan un conjunto de fuerzas psíquicas que no pueden representar un esquema ni una estructura organizada. Sólo en el sueño, estado donde se hacen solubles las imágenes, éstas ganan adherencia a la idea de realidad. El individuo que está soñando vive en una suerte de realidad-imagen, cuya coherencia es solo circunstancial; allí se conjugan diversos elementos de la percepción de manera anárquica al margen de cualquier causalidad. Sin embargo, el hecho de que una imagen pueda estar seguida de otra, o de un sonido, o de una frase, debe obedecer, dirá Freud (2004), a una relación de elementos comunes, que se unen libremente. No hay un vínculo a un estado anterior que provea de coherencia a las manifestaciones psíquicas.

Ni Bergson ni Freud descubren en la imagen una instancia ontológica. Incluso, la relación imagen-realidad que puede abrirse paso en estas teorías resulta antagónica, o así bien puede hacerlo ver cierta lectura de ellas. En el primer caso porque la imagen como proyección de un esquema inmóvil desmiente la realidad de la conciencia que es duración. En el caso de Freud, la imagen puede entenderse como manifestación deformada de unas fuerzas profundas o de procesos inconcientes que están dirigidos a satisfacer instintos y deseos, en consecuencia, tampoco representan un vínculo estable a la realidad psíquica, su condición es accidental y circunscrita a una realidad superior. En general, las posturas psicologistas no lograrán recomponer el vínculo entre imagen y realidad, por lo menos no antes de la segunda mitad del siglo XX. Sin embargo puede argüirse que en ambos enfoques la imagen adquiere al menos el papel de manifestación. Entiéndase en ambos casos que la realidad, que ha sido exiliada a las profundidades de la psiquis del hombre, esa realidad oculta pero 
latente, quiere derivar hacia lo conciente. De tal suerte que, tanto los recuerdos como las pulsiones devienen en imágenes.

En el camino de la tradición psicoanalítica está inevitablemente referida la obra de Lacan, a través de la cual se releen las posturas freudianas. Si bien a partir de Lacan la idea de imagen gana relevancia, en la matriz de esta tradición, la imagen no alcanzará el status que le incorpore a la ciencia, fundamentalmente porque no resulta inteligible por sí misma, en otras palabras, no es la imagen la que permite leer la realidad. Desde este punto de vista, la cuestión permanecerá en una especie de ortodoxia donde el lenguaje sigue siendo el vector sobre el que se pretende la comprensión de los fenómenos psíquicos.

En un primer momento, hacia la mitad del siglo, la propuesta de Lacan logró poner el acento en la imagen como instancia fundamental de la realidad mediante su tesis denominada la fase del espejo, en la cual explica cómo la constitución del sujeto pasa por una primera y primordial fase, en la que éste logra identificarse con una imagen de sí que apenas vislumbra. La imagen tiene, según esta tesis, preponderancia sobre el lenguaje. El argumento central es que el yo se construye fundamentalmente en su Imago. $Y$ esto sucede antes de "objetivarse en la dialéctica de la identificación con el otro y antes de que el lenguaje le restituya en lo universal su función de sujeto" (Lacan 1949 2).

Sin embargo, más temprano que tarde, la lectura que hará Lacan de Freud priorizará el lenguaje sobre lo imaginado. Bajo esta perspectiva, aquella caótica producción de imágenes que cunden dominantemente en la psiquis del hombre constituye en Lacan una suerte de estructura simbólica, en virtud de la cual, los fenómenos psíquicos logran cierta legibilidad. De tal modo y a pesar de que las imágenes se producen en los sueños con extremada complejidad, se admite como trasfondo de éstos una estructura organizada sobre el lenguaje, es decir, funcionando a partir del equivalente entre significado y significante. No significa sin embargo que haya una correspondencia unívoca entre las imágenes y un significado. Lo que une a la imagen con el significado 
se entiende en virtud a una función simbólica, vínculo en el que se constituye lo imaginario.

La aprehensión de ese elemento imaginario, de lo que Freud definió como la realidad esencial resume la búsqueda del psicoanálisis: EI imaginario termina por definirse en el intercambio analítico y no en la imagen, es decir, que lo imaginario emerge como palabra, porque "está hecho para expresarse, para simbolizarse, para ser dicho, para simbolizar algo, y algo que difiere según el momento del diálogo" (ídem), mientras la imagen no logra mantener su correspondencia con la realidad, ha sucumbido al lenguaje. Una vez que éste ha emergido, sin saber cómo ni cuándo, ya nada ha de tener significado fuera de él. Allí está el centro de este asunto, la imagen es posible a la ciencia por el lenguaje. En consecuencia todo lo que tiene de logicidad el lenguaje se incorpora no sólo en la semántica sino a la realidad de la imagen.

\section{La Imagen como síntesis de sensaciones}

La imagen, como producto del discurso contemporáneo, logra connotar una dimensión más ampliada y profunda, en tanto síntesis de comprensión de la realidad y no sólo representación o figuración. Los adelantos en la neurociencia han impulsado el entendimiento de la imagen como algo interior y no sólo como algo mental; esta nueva imagen compone otros tipos de sensaciones que dan cuenta de una realidad kinestésica. Las imágenes así entendidas, son ideas de la realidad que se forman en la complejidad de los sentidos y no solamente figuras que representan lo visto. Tal forma de comprensión se ha abierto paso desde Bergson y sobreviene a través de la psicología científica y la neurociencia: Su conclusión es que existe un ámbito físico-motor que surte lo imaginario. El esquema motor de Bergson sería, más que un conjunto de imágenes, un conjunto de sensaciones kinestésicas. Piaget se había referido a la etapa sensoriomotora como aquella donde se crean esquemas de conducta que permiten actuar pero al mismo tiempo conocer el espacio. Lo propio había hecho Lacan con su referida teoría acerca del estadio del espejo, donde 
muestra la transformación producida en el sujeto cuando asume una imagen de él mismo.

Pero sólo traspasada la mitad del siglo, la cuestión tomaría otro fondo científico impulsada por el trabajo de Hebb en 1949, quien propondría que la actividad neuronal conducirá al desarrollo de una "asamblea celular", la cual persiste tiempo después de ocurrido un estímulo; este aporte sirvió para entender que las sensaciones no se producen con exclusividad a un tipo de estímulo, sino que se despliegan en un área localizable del cerebro. Después de esto se hizo posible entender que varias clases de sensaciones se dieran en un mismo acto perceptivo.

Al cabo de la segunda mitad del siglo la idea de imagen habría usufructuado de una enorme cantidad de aportes, sobre todo de tipo neurocientífico, que la alejaban del dominio del lenguaje y la situaban justo en el centro del problema del pensamiento. Arnheim (1984) considera que las formas no son otra cosa que configuraciones de fuerzas, lo que comprueba la cualidad dinámica de la visión y desestima la concepción de que el mundo visual es una aglomeración de objetos estáticos; en consecuencia, considera que las estructuras compositivas de la obra de arte discurren en términos de vectores y no de formas u objetos. Entretanto, Damasio refleja la certidumbre con la que la neurociencia terciará en favor de la imagen, una vez que los signos del lenguaje lucen arbitrarios frente a los procesos profundos en los que se creen constituidas las formas de organización cognitiva. Para él, tanto símbolos como palabras se hacen imágenes, y existen, antes de ser habladas o fraseadas, como imágenes auditivas o visuales en la conciencia.

El hecho es pues, que probablemente el principal contenido de nuestros pensamientos son imágenes, con independencia de la modalidad sensorial en la que son generadas y de si se refieren a una cosa o a un proceso que implica cosas; o acerca de palabras u otros símbolos, en un lenguaje determinado, que corresponden a una cosa o proceso. (Damasio 1996 108).

La conclusión es que la imagen se halla, bajo esta óptica, desprendida de la figura y de su capacidad de representación, su realidad es aquella 
que la integra a la actividad senso-motora del organismo; hablar de imágenes tendría sentido en la forma como se interioriza el mundo externo (Llinás 2003).

\section{Hacia una lógica icónica}

Las teorías que iban a acercar más a la imagen al dominio de las Ciencias Sociales habrían de enfrentar los dilemas en torno a la divergencia imagen-lenguaje, dando apertura a una interpretación distinta, que se cierne sobre la naturaleza falible del lenguaje. La crítica hacia Lacan provendría de esta dirección. ¿Cómo ha de ser posible una estructura preeminente a los fenómenos psíquicos? Y ¿en qué instancia ha de entenderse la existencia de tal estructura? La cuestión para Laplanche (1992) es que toda tópica parte del yo, y por tanto será imaginaria, como cualquier forma estructurada que se quiera atribuir al aparato psíquico. El inconciente sería -según la fórmula de Laplanche- lenguaje pero sin estructura, o por lo menos no una estructura de la manera perfecta, algorítmica y binaria que se ha tenido por posible. La relevancia del lenguaje se mantiene considerando que, al menos en un sentido amplio, el inconciente es un fenómeno de significación, pero se trata de un "lenguaje" que no se impone como una función de correspondencia entre significado y significante. La realidad del inconciente no atañe a la palabra como una unidad estructurante sino a la palabra como otra cosa.

Por su parte Castoriadis habría planteado algo similar en consideración a que el lenguaje no embarga una lógica anterior a la realidad instituida, es decir, que las significaciones no tendrían una esencia supra-social que haya de ser buscada en la naturaleza o en la pura racionalidad; lo imaginario mismo, como potencia de instituir y alterar, es anterior a lo simbólico. La psiquis es provista de significación y valor por el imaginario social, incluso la coherencia y la comunicabilidad de los significados son posibles en virtud de lo imaginario. Lo específico de lo humano parece consistir, según Castoriadis, en no poder remontarse a los orígenes de su condición, de allí entonces que no puede el lenguaje suponerse a partir de la psique, pues ésta no lo produce (Castoriadis 2007). 
La insistencia sobre el signo como forma de comprensión de la realidad psíquica termina por agotar, según Camino (1989), la misma terapia psicoanalítica. La imagen tendría, a diferencia de la palabra, la capacidad de unir la acción con el desarrollo de la terapia, como quiera que ésta se halle en el seno de una realidad más profunda que afecta al ser humano. La reivindicación de la imagen va a depender, en la perspectiva contemporánea, de la profundidad que se le atribuya frente al papel del lenguaje; mucho más cuando éste tiende a interpretarse como artificioso, como un acuerdo que se pone en práctica, más que un vínculo en el que se puede reconocer el carácter de una sociedad.

La crítica al dominio del lenguaje hace puente hacia una nueva forma de pensamiento en la imagen. Boehm (2006) reitera que sólo a través de una crítica semejante, que pueda tomar distancia del empobrecido concepto de logos, producto del pensamiento estructural de la lingüística, se puede restituir a la imagen sus "derechos fundacionales y su función de demostración" (98). No se trata de que mediante la crítica se quiera subsumir a la imagen en la órbita del logos, sino que a la inversa, se admita su dependencia respecto a ella, se admita que son las evidencias icónicas e intuitivas las que ayudan a la realización del lenguaje (ídem). La pregunta que queda abierta es por las maneras en las que esto pueda ser posible. Pregunta que Boehm reitera: "¿Cómo producen sentido las imágenes?". Para responder a ello, han de solucionarse un par de cuestiones más básicas: ¿Cómo adquieren significado las imágenes? Y en consecuencia, ¿cómo el significado puede articularse a sí mismo sin recurrir a modelos lingüísticos o a instrumentos retóricos? Boehm intenta responder a lo anterior admitiendo la cuestión de que el logos sería el ícono; los íconos son capaces de reflejar la realidad, pero no constituyen el logos del lenguaje, pues tienen unas maneras no permanentes de asociación y significación, lo que sin embargo no impide que se produzca en ellas unas reglas que las hacen inteligibles; reglas que tienen que ver con fenómenos visuales como el contraste.

Más allá del lenguaje existen poderosos espacios de sentido, insospechados espacios de visualidad, de tonalidad, de gestos, de mímica 
y de movimiento, que no necesitan ser mejorados o justificados a posteriori por la palabra (p. 105).

La cuestión puede remitir al análisis pictórico de Deleuze (2002), quien sugiere una especie de matters of fact (p. 88) que dé cuenta de la relación entre las figuras en un cuadro, en consideración a un sentido, o mejor, a un ritmo que las recoge, distinto al narrativo y al figurativo; tal relación rehúsa una conexión a priori entre causa y consecuencia. Las leyes que Deleuze atribuye al tríptico connotan una serie de fuerzas que atraviesan la pintura, pero estas leyes no tienen que ver con una fórmula, forman parte de esta lógica irracional, o de esta lógica de la sensación que constituye la pintura ( $p$. 86). En otras palabras, se hace posible diferenciar entre la lógica del lenguaje y una lógica generadora de sentido dentro de las imágenes; esta última inadmisible a la ortodoxia científica y académica, en la medida en que lo lógico no puede ir asociado a lo imaginativo, pues la simple suposición de esto, es ya una contradicción en el dominio de las inferencias admitidas.

Cuanto más profundo ha logrado llegar la cuestión misma de la imagen, en boga dentro de la filosofía actual, más se ha puesto en evidencia el desafuero de la lógica y con ello del lenguaje. Las formas cientificistas de abordar el estudio de la cultura, apoyadas enteramente en el lenguaje, en la unidad del concepto, en la realidad dicha, ceden cada vez más su lugar a la imagen como objeto de intelección de la realidad social. La afirmación de un vínculo entre significación e imagen, y más que eso, la comprensión de la imagen como el terreno propio de la significación, conseguirá a la larga renovar el conocimiento de las culturas, con una cada vez mayor proximidad a las pequeñas atmósferas, a lo cotidiano y a lo sentido.

\section{Conclusiones}

La relación entre la imagen y la significación atravesó sinuosamente el siglo XX sin marcar de fondo un curso evolutivo sobre el cual reivindicar el vínculo entre imagen y realidad, más bien estuvo emplazada en una serie de posturas que se fueron dando yuxtapuestas, sin sucesión y en 
el desarrollo de campos de conocimiento distintos. Al pensar que existe un vínculo entre la imagen y la realidad no se pretende otra cosa que afirmar a la imagen en el origen del sentido, entendiendo que éste no se completa abstraído de la imagen. Tal pretensión se mantuvo latente a pesar de todo el peso de la tradición, aunque su entendimiento y desarrollo sólo pudieron darse como parte de una nueva forma de ver del lenguaje, incluso puede decirse que la comprensión de ese vínculo imagen-realidad, dependió de cuán socavado se halló el paradigma que naturalizaba la identidad entre lenguaje y pensamiento.

Poco servía el creciente interés en la imagen durante el siglo XX si no se lograba hacer mella en la hegemonía del lenguaje como sistema de reglas unívocas. La semiótica extendió su análisis a las imágenes pero terminó por subsumirlas al interior de un sistema de valores, asumiendo de fondo que pueden leerse como signos lingüísticos; Husserl absuelve a la imagen de la limitada concepción que la mantenía como copia y representación, pero niega a su vez que en ella se logre la síntesis del significado; mientras que la aparente relevancia de las imágenes en la comprensión de la psiquis no excedería la dimensión lógica en la que el psicoanálisis relaciona las manifestaciones concientes con el inconciente que las provoca. Muchas de las teorías que aportaron a la comprensión de la imagen no lograron empero, entenderla como una instancia irreductible a la lógica del lenguaje. Castoriadis (1999), al referirse al papel del psicoanalista, renueva la apuesta lacaniana, refiriéndose a una dimensión lógica que quiere captar el papel conjuntista - identitario del mundo psíquico (p. 221). A pesar de que esta dimensión no agota por completo lo real, este planteamiento llama la atención sobre el esfuerzo lógico que supone la tarea de construir y presentar el sentido de lo inconciente, lo cual resulta asonante con la idea de Villafañe (2006), quien habla de un esquema preicónico como base para la percepción de las imágenes, de modo que la observación de un objeto supone la abstracción de sus elementos estructurantes; por ese camino termina concluyendo que la composición de la imagen, al igual que la sintaxis, puede seguir un principio básico de simplicidad, al cual denomina "normativa", y a través del cual explica la forma como se ordenan los elementos icónicos en un sentido de eficacia visual. 
Tres factores pueden sugerir el rompimiento con la tradición durante el siglo XX, y asociarse a su manera, con el actual horizonte de comprensión en el que se une la imagen y la significación.

1. Sartre entendió que la clave era comprender que la imagen no era distinta a su significación, pues ésta ya es el saber de algo y no demanda una conciencia que le integre, lo cual difiere de la postura dominante que impulsa a creer en una instancia anterior a la cual la imagen acude como contenido psíquico.

2. Por su parte, la relación entre el lenguaje y la realidad se verá menoscabada por una creciente conciencia acerca de los límites del lenguaje. Según Rorty el lenguaje no representa ya un puente que conecta al pensamiento con una realidad fuera de él, sino que constituye la urdimbre misma con la que se construyen mundos distintos.

3. Y el tercer factor a considerar, es la concepción que tomó forma en la medianía del siglo y que relacionó la imagen con la formación de sensaciones internas más allá de la idea de ésta como hecha de contornos inmóviles. La idea de Sartre, Bergson y Piaget es que la imagen comporta impresiones kinestésicas en las que se sintetiza el sentido, algo que se verá soportado en el advenimiento de la neurociencia y en los aportes de tipo teórico venidos desde el arte.

\section{Bibliografía}

Arnheim, R. El poder del Centro. Estudio sobre la composición en las artes visuales. Madrid: Alianza Editorial. 1984.

Arnheim, R. El pensamiento visual. Barcelona: Paidós. 1986.

Barthes, R. La aventura semiológica. Barcelona: Paidós. 1997.

Barthes, R. Elementos de la Semiología. Barcelona: Alberto Corazón. 2000.

Bergson, H. Memoria y Vida. Barcelona: Altaya. 1994.

Boehm, G. ¿Más allá del lenguaje? Apuntes sobre la lógica de las Imágenes. En A. García (Ed.), Filosofía de la Imagen (pp. 87-106). Salamanca: Universidad de Salamanca. 2006. 
Camino, Lluís. "Hermes y la psicoterapia". En A. Verjat (Ed.), El retorno de Hermes. Hemenéutica y Ciencia Humanas (72-95). Barcelona: Anthropos. 1989.

Cassirer, E. Filosofía de las formas simbólicas III. Fenomenología del reconocimiento. México: Fondo de Cultura Económica. 1998.

Castoriadis, C. Figuras de lo pensable. Madrid: Frónesis. 1999.

Castoriadis, C. La institución imaginaria de la sociedad. Buenos Aires: Tusquets Editores. 2007.

Courvez, Maurice. Los estructuralistas. Foucault, Lévi Strauss, Lacan, Althusser y otros. Buenos Aires: Amorrortu. 2005.

Damasio, A. El error de Descartes. La emoción, la razón y el cerebro humano. Barcelona: Crítica. 2006.

Deleuze, G. Francis Bacon. Lógica de la sensación. Madrid: Arena libros. 2002.

Durand, G. De la mitocrítica al mitoanálisis. Figuras míticas y aspectos de la obra. Barcelona: Anthropos. 1993.

Freud, S. La Interpretación de los sueños 1. Madrid: Alianza Editorial. 2004.

Heidegger, M. Hölderlin y la esencia de la poesía. Barcelona: Anthtopos. 1994.

Husserl, E. Investigaciones Lógicas I (Versión Morente y Gaos). Madrid: Alianza. 1999.

Lacan, J. El estadio del espejo. El estadio del espejo como formador de la función del yo (je) tal como se nos revela en la experiencia psicoanalítica. 1949. Recuperado de http://www.pueg.unam.mx/diversidad/ images/stories/pdf/M_VI/ lacan-espejo.pdf

Laplanche, J. El estructuralismo frente al psicoanálisis. Recuperado de http:// www.revistaalter.com/Revistas/Numero6/El_estructuralismo frente_al_psicoanalisis.htm

Llinás, R. El cerebro y el mito del yo. El papel de las neuronas en el pensamiento y el comportamiento humanos. Bogotá: Norma. 2003.

Sartre, J. P. Lo Imaginario. Psicología fenomenológica de la imaginación. Buenos Aires: Losada. 2005.

Villafañe, J. Introducción a la teoría de la imagen. Madrid: Pirámide. 2006. 